\title{
Synthesis, characterization and modeling of self-assembled porphyrin nanorods
}

\author{
Danielle Laurencin ${ }^{a}$, Pascal G. Yot ${ }^{a}$, Christel Gervais $^{b}$, Yannick Guari ${ }^{a}$, Sébastien \\ Clément $^{\mathrm{a}}$, Erik Elkaim ${ }^{\mathrm{c}}$, Matthieu Paillet ${ }^{\mathrm{d}}$, Didier Cot $^{\mathrm{e}}$, and Sébastien Richeter ${ }^{\mathrm{a}, *}$ \\ a Institut Charles Gerhardt de Montpellier, ICGM, UMR 5253, CNRS UM ENSCM, 34095 Montpellier, France \\ b Laboratoire de Chimie de la Matière Condensée de Paris, LCMCP, UMR 7574, Sorbonne Université, Collège de \\ France, 75005 Paris, France
}

c Synchrotron SOLEIL, L'Orme des Merisiers Saint-Aubin, BP 48, 91192 Gif-sur-Yvette, France

d Laboratoire Charles Coulomb, L2C, UMR 5221, CNRS UM, 34095 Montpellier, France

e Institut Européen des Membranes, IEM, UMR 5635, Université Montpellier, ENSCM, CNRS, 34095 Montpellier, France

This paper is part of the 2019 Women in Porphyrin Science special issue

Received date (to be automatically inserted after your manuscript is submitted) Accepted date (to be automatically inserted after your manuscript is accepted)

\begin{abstract}
Porphyrin nanorods were prepared by ion-association between free base meso 5,10,15,20tetrakis-(4- $N$-methylpyridinium)porphyrin cations and tetraphenylborate anions. The nanorods had variable length (up to a few micrometers long) and diameters $(\sim 50-500 \mathrm{~nm})$. Their structure at the molecular level was elucidated by combining multinuclear solid state NMR spectroscopy, synchrotron Xray powder diffraction and DFT calculations.
\end{abstract}

KEYWORDS: porphyrin, nanorods, self-assembly, solid state NMR, NMR cristallography, DFT modeling

*Correspondence to: Sébastien Richeter, Institut Charles Gerhardt Montpellier, ICGM, UMR 5253, CNRS, Université de Montpellier, ENSCM, Place Eugène Bataillon, 34095 Montpellier cedex 5 (France). E-mail : sebastien.richeter@umontpellier.fr. Tel. : $++(33) 467143971$. 


\section{INTRODUCTION}

Natural photosynthetic light-harvesting systems such as chlorosomes of green photosynthetic bacteria play key roles such as photon capture and energy transfer. Chlorosomes of green photosynthetic bacteria are very efficient natural light harvesting complexes [1]. They contain on the order of $10^{5}$ bacteriochlorophyl molecules which are organized into rod-shaped aggregates [2]. Porphyrins are attractive compounds for the design of materials having advanced properties such as photonic wires [3], nonlinear optical materials [4], photovoltaic cells [5] or artificial photosynthetic reaction centres [6]. To avoid complicated multi-step synthetic procedures to obtain multiporphyrinic systems [7], molecular self-assembly processes are attractive for preparing porphyrin nanoparticles [8,9], nanorods [10,11], nanofibers [12], nanotubes [13], and other nanostructures with different morphologies [14].

The self-organization of porphyrin derivatives into nanoscale superstructures is generally driven by non-covalent interactions such as van der Waals forces, hydrogen bonding, $\pi-\pi$ interactions, ionic interactions and/or coordinative binding [14]. Investigation of the morphology of these nanostructures is usually performed using imaging techniques like transmission electronic microscopy (TEM), scanning electronic microscopy (SEM) or atomic force microscopy (AFM) [8-14]. UV-visible absorption spectroscopy can also be helpful to determine if porphyrins self-assemble to form $J$ - or $H$-aggregates: the Soret absorption is generally redshifted upon formation of $J$-aggregates, while it is blueshifted upon formation of $H$-aggregates [15]. If sufficiently crystalline materials are obtained, X-ray powder diffraction (XRPD) data can also be used to determine space group, unit cell dimensions and some important structural parameters like interplanar distances, which may also be observed by HR-TEM (High Resolution TEM) [16,17]. According to the obtained data, models can be proposed to show how porphyrins and other molecular species are assembled [18]. Moreover, multinuclear solid state NMR has been used in a small number of cases [19].

In this manuscript, we present the synthesis and full characterization of self-assembled porphyrin based nanorods made of free base meso 5,10,15,20-tetrakis-(4- $N$-methylpyridinium)porphyrin cations $\left(\mathbf{T M P y P} \mathbf{P}^{4+}\right)$ and tetraphenylborate anions $\left(\mathbf{B P h}_{4}^{-}\right)$(Chart 1). These two building blocks were previously used for the synthesis of porphyrin nanoparticles without self-aggregation $[20,21]$. Here, it will be shown how detailed information on the mode of association of these building blocks at the nanoscale can only be reached by combining a wide diversity of analytical techniques (including synchrotron powder X-ray diffraction and multinuclear solid state NMR) to $a b$ intio DFT calculations. The characterization strategy described herein should therefore be of interest to the study of a variety of other porphyrin nanostructures.

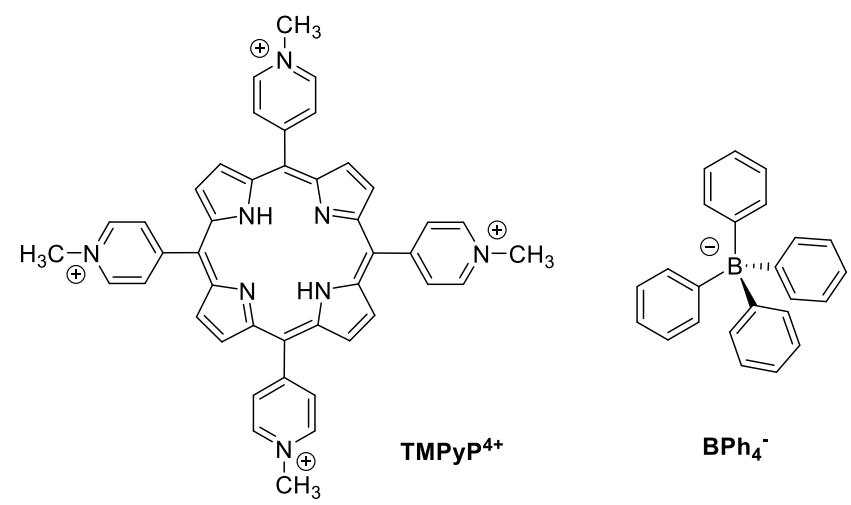

Chart 1. Structures of the $\mathbf{T M P y P} \mathbf{P}^{4+}$ and $\mathbf{B P h}_{4}{ }^{-}$building blocks for the synthesis of porphyrin nanorods.

\section{RESULTS AND DISCUSSION}




\section{Synthesis and morphology of porphyrin nanorods.}

Meso-5,10,15,20-tetrakis-(4- $N$-methylpyridinium) porphyrin $\left(\mathbf{T M P y P} \mathbf{P}^{\mathbf{4}}\right)$ is a water-soluble cationic porphyrin, which has been actively used as a water-soluble porphyrin derivative for various biomedical applications, where it can play the role of a photosensitizer for photodynamic therapy (PDT) applications [22,23] or as ligand able to bind DNA structures like G-quadruplexes [24-27]. TMPyP ${ }^{4+}$ has also been used as a cationic building block to obtain self-

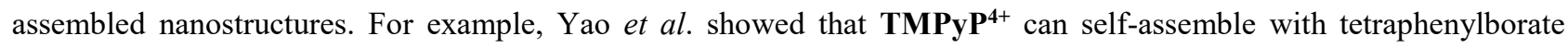
$\left(\mathbf{B P h}_{4}{ }^{-}\right)$in water to form spherical organic nanoparticles with an average diameter of $25 \pm 3 \mathrm{~nm}$ [20,21]. These ion-pairbased nanoparticles could be sterically stabilized with polyvinylpyrrolidone (PVP). Here, by avoiding the use of PVP and using slightly different reactions conditions, we were able able to synthesize porphyrin based nanorods using these same ions.

In our synthetic approach, the solvent system we used for the preparation of nanorods was a $3: 1(v: v) \mathrm{EtOH} / \mathrm{H}_{2} \mathrm{O}$ mixture, and the final concentrations of the $\mathbf{T} \mathbf{M P y} \mathbf{P}^{4+}$ and $\mathbf{B P h} \mathbf{4}^{-}$ions in the reaction mixture were fixed at 0.03 and $0.12 \mathrm{mM}$, respectively (i.e. four equivalents of tetraphenylborate anions compared to the porphyrin). Reactions were performed during 24 hours at $15^{\circ} \mathrm{C}$ and $30^{\circ} \mathrm{C}$. Upon mixing $\mathbf{T M P y P I}$ with $\mathbf{N a B P h}_{4}$, an immediate change in color from purple to orange occurred as a consequence of the aggregation of the two building blocks. However, no immediate precipitation was observed thanks to the presence of EtOH, allowing UV-visible absorption spectroscopy analyses to be performed in the early stage of the reaction (10 minutes after mixing $\mathbf{T M P y P I}$ with $\mathbf{N a B P h}$ ). The spectra obtained confirmed that aggregated species are formed since the Soret absorption band of $\mathbf{T M P y \mathbf { P } ^ { + + }}$ in the reaction mixture was broader and bathochromically shifted compared to the Soret absorption band of $\mathbf{T M P y} \mathbf{P}^{4+}$ alone in $\mathrm{H}_{2} \mathrm{O}$ (Figure 1a). The four Q bands also appeared to be bathochromically shifted. This spectral evolution could be in agreement with a flattening of the porphyrin and a larger $\pi$ conjugation between the porphyrin core and the meso pyridinium groups (vide infra, X-ray powder diffraction analysis and DFT calculations). After 24 hours at $15^{\circ} \mathrm{C}$, a mixture of nanofibers with nanoparticles stuck onto them was observed by TEM. When the same reaction was performed at $30^{\circ} \mathrm{C}$, nanorods of variable length (up to a few micrometers long) and diameter ( 50-500 nm) were formed. These nanorods could be rather well dispersed according to TEM and AFM (Figures $1 \mathrm{~b}$ and 1d), but tended to form bundles upon removing the solvent mixture, as it can be seen by SEM (Figure 1c). A few milligrams of brown nanorods could be isolated in the solid state, which were then studied by solid state NMR and XRD.

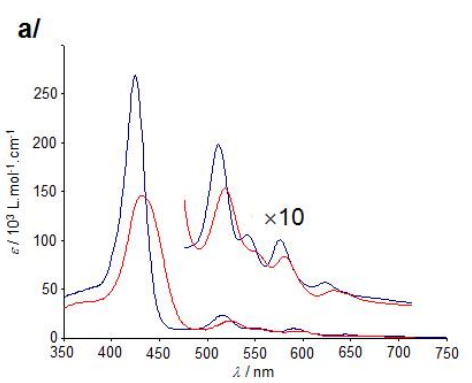

b/

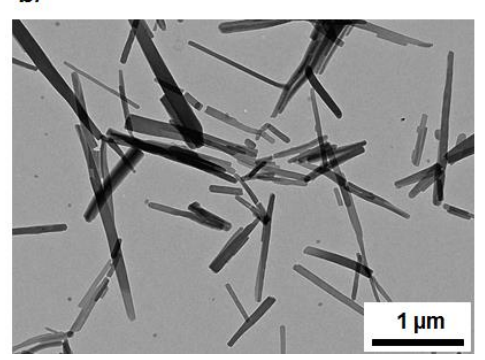

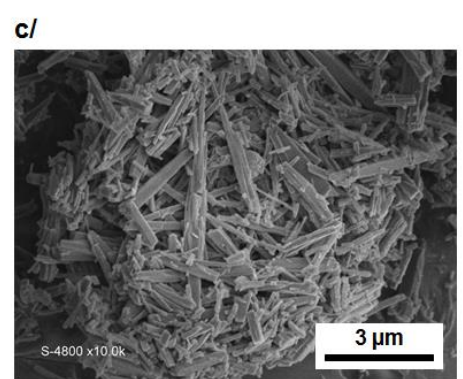

d/

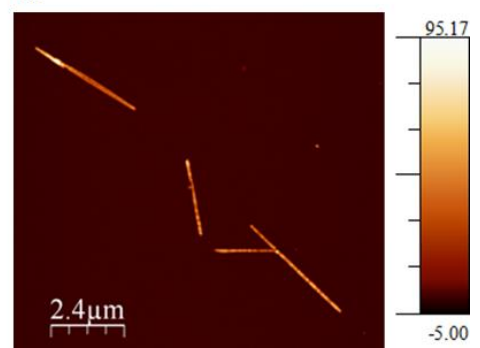


Fig. 1. a/ UV-visible absorption spectra of the $\mathbf{T M P y P}^{4+}$ precursor (blue) and of the reaction mixture after 10 minutes of reaction (red) in EtOH/ $\mathrm{H}_{2} \mathrm{O} 3: 1$. b/ TEM, c/ SEM and d/ AFM images of the nanorods.

\section{Solid state NMR analyses}

Multinuclear MAS (magic angle spinning) solid state NMR analyses were carried out on the isolated nanorods, in view of bringing direct evidence that these are formed by association of $\mathbf{T M P y P} \mathbf{P}^{\mathbf{4}}$ and $\mathbf{B P h} \mathbf{4}^{-}$ions (Figure 2). First, it is clear that NMR signatures characteristic of both $\mathbf{T M P y} \mathbf{P}^{4+}$ and $\mathbf{B P h} \mathbf{4}^{-}$building-blocks can be observed on the ${ }^{1} \mathrm{H},{ }^{13} \mathrm{C}$ and/or ${ }^{11} \mathrm{~B}$ solid state NMR spectra of the nanorods. For example, the ${ }^{1} \mathrm{H}$ resonance centered at $\sim-3 \mathrm{ppm}$ is characteristic of the internal $\mathrm{NH}$ of the porphyrin, the ${ }^{13} \mathrm{C}$ resonance centered at $43 \mathrm{ppm}$ belongs to the methyl group of the meso 4-N-methylpyridyl moiety of the porphyrin, while the ${ }^{11} \mathrm{~B}$ resonance observed by ${ }^{11} \mathrm{~B}$ NMR can only be assigned to tetraphenylborate anions. Second, it is also clear from the ${ }^{1} \mathrm{H},{ }^{13} \mathrm{C}$ and ${ }^{11} \mathrm{~B}$ MAS NMR spectra that the local environments of the $\mathbf{T M P y P} \mathbf{P}^{4+}$ and $\mathbf{B P h}_{4}{ }^{-}$building blocks within the nanorods differ from those of the starting reagents. For instance, when considering the characteristic resonances mentioned previously, the ${ }^{1} \mathrm{H}$ resonance of the porphyrin $\mathrm{NH}$ is deshielded in the nanorods, the ${ }^{13} \mathrm{C}$ resonance of the methyl group in the meso 4-N-methylpyridyl moiety is more shielded than in the porphyrin precursor, and the ${ }^{11} \mathrm{~B}$ signal of the tetraphenylborate ions is much broader in the nanorods than in the $\mathrm{Na}$ salt used in the reaction.
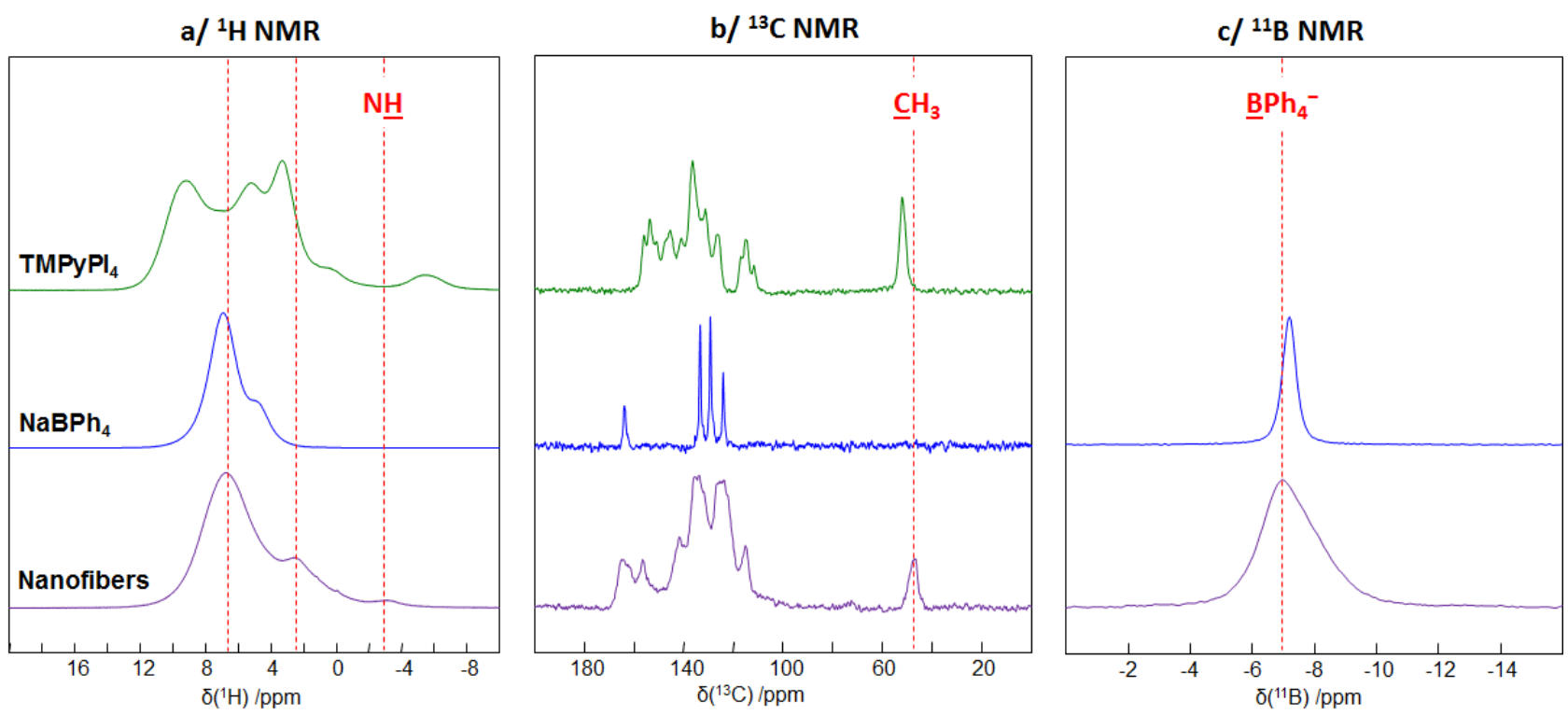

Fig. 2. Solid state NMR spectra of $\mathrm{TMPyPI}_{4}$ (green), $\mathbf{N a B P h}_{4}$ (blue) and the porphyrin nanorods (purple) recorded at $14.1 \mathrm{~T}$ under MAS, for (a) ${ }^{1} \mathrm{H}$, (b) ${ }^{13} \mathrm{C}$ and (c) ${ }^{11} \mathrm{~B}$. Details on the acquisition conditions can be found in the experimental section.

Using two-dimensional ${ }^{1} \mathrm{H}-{ }^{11} \mathrm{~B}$ correlation experiments, in which the "through-space" proximity between ${ }^{1} \mathrm{H}$ and ${ }^{11} \mathrm{~B}$ nuclei is probed (through the dipolar coupling interaction), complementary informations on the association between $\mathbf{T M P y P}^{4+}$ and $\mathbf{B P h}_{4}^{-}$ions was obtained. Indeed, as shown on the CPMAS (cross polarization magic angle spinning) NMR spectra in Figure 3, an interesting cross-peak is first observed for a contact time (CT) of 4 ms, between the ${ }^{11} \mathrm{~B}$ resonance of the $\mathbf{B P h}_{4}{ }^{-}$ion and a ${ }^{1} \mathrm{H}$ resonance centered at $\sim 2 \mathrm{ppm}$ (orange circle). Given that this ${ }^{1} \mathrm{H}$ resonance belongs tothe protons of the porphyrin $\underline{\mathrm{CH}}_{3}$ group (see Figure $\mathrm{S} 1$, supporting information), such analyses confirm the spatial proximity of the two ions within the nanorods. When increasing the contact time to $8 \mathrm{~ms}$, an additional crosspeak is observed, correlating the ${ }^{11} \mathrm{~B}$ resonance of the $\mathbf{B P h}_{4}^{-}$ion and a ${ }^{1} \mathrm{H}$ resonance centered at $\sim-3 \mathrm{ppm}$, which 
belongs to the $\mathrm{N} \underline{\mathrm{H}}$ of the porphyrin (green circle). The need for longer contact times to observe this cross-peak suggests that within the nanofibers, both ions are associated in such a way that the $\mathrm{B}$ atoms are closer to the $\underline{\mathrm{C}}_{3}$ protons than the $\mathrm{N} \underline{\mathrm{H}}$.
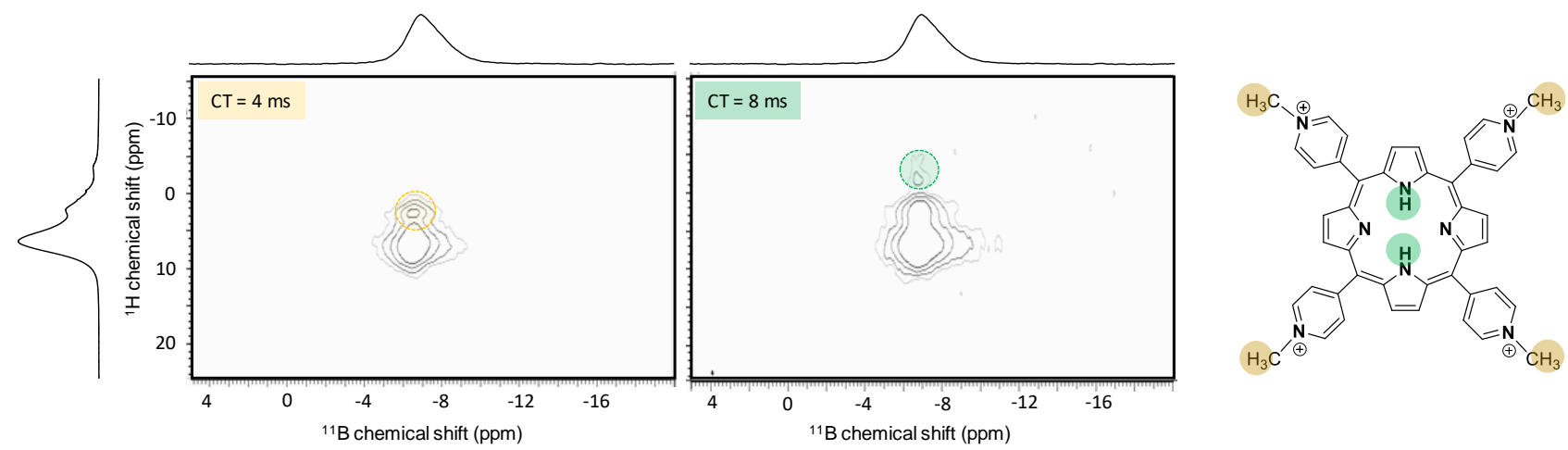

Fig. 3. ${ }^{1} \mathrm{H}-{ }^{11} \mathrm{~B}$ CPMAS NMR spectra of the porphyrin nanofibers recorded at $14.1 \mathrm{~T}$ under MAS, using contact times (CT) of 4 ms (left) and $8 \mathrm{~ms}$ (right). The cross-peak highlighted in orange at CT $=4 \mathrm{~ms}$ attests of a close proximity between the boron of $\mathbf{B P h}_{4}^{-}$ and methyl group of the porphyrin, while the cross-peak highlighted in green at CT= $8 \mathrm{~ms}$ shows that the $\underline{\mathrm{H}}$ of the porphyrin is more distant from the $\mathbf{B P h} \mathbf{4}^{-}$anion. The projections shown along both axes correspond to the $1 \mathrm{D}{ }^{1} \mathrm{H}$ and ${ }^{11} \mathrm{~B}$ MAS NMR spectra.

\section{X-ray powder diffraction analysis and DFT modeling}

In order to go further into the structural analysis of the nanorods, and to provide deeper insight into the mode of association of the cationic and anionic building blocks at the molecular level, high-resolution synchrotron X-ray powder diffraction (S-XRPD) analyses and computational modeling were used. It should be noted that due to the "nano" nature of these particles, and their tendency to aggregate in the dry state, no crystals of sufficient size and quality could be isolated for single-crystal X-ray diffraction studies. Here, the S-XRPD data were collected at $125 \mathrm{~K}$ and at room temperature at the Soleil synchrotron (Gif-sur-Yvette, France) on the CRISTAL beamline, and the powder patterns were examined using the FoX (Free Objects for Crystallography) software, in order to determine the unit cell parameters. Results for the two considered temperatures are represented in Figures 4a (below) and S2 (Supporting Information), and the full unit cell parameters at both temperatures are provided in Table S1 (Supporting Information).

For the data obtained at $125 \mathrm{~K}$, a preliminary structural model was derived from the powder pattern using FoX,

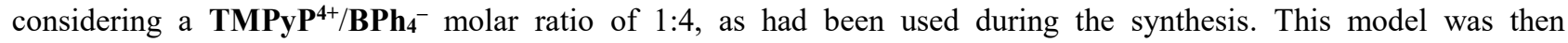
optimized using DFT, by relaxing all atomic positions but keeping cell parameters fixed to the experimental values. It should be noted that relaxation of all atomic positions (and not $\mathrm{H}$ positions only) was found to be critical at this step to achieve a suitable geometry for the two building blocks, and also to obtain a better agreement between experimental and DFT-calculated NMR parameters. This is demonstrated in Fig. $4 \mathrm{~b}$, in which the experimental ${ }^{13} \mathrm{C} \mathrm{CPMAS}$ spectrum of the nanorods is compared to the calculated ${ }^{13} \mathrm{C}$ shifts for two structural models, obtained after relation of all atomic positions or of $\mathrm{H}$ atoms only. A better agreement is obtained in the former case, and this is also true when performing similar analyses of the experimental $v s$ calculated ${ }^{11}$ B NMR data (Tables S2 and S3 in the Supporting Information). 

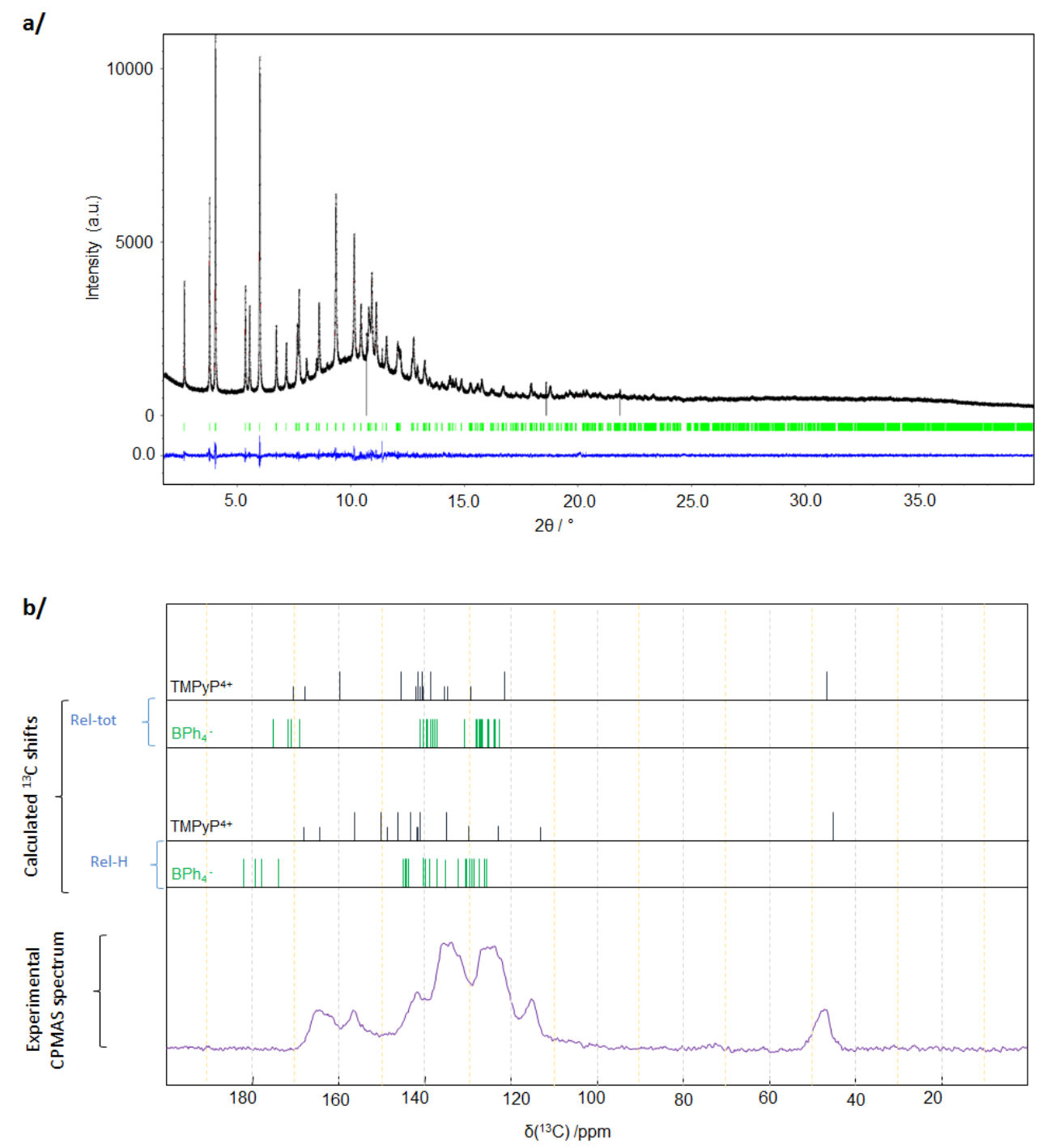

Fig. 4. a/ Structure-independent refinement of the unit-cell of the diffraction pattern obtained for the nanorods at $125 \mathrm{~K}$. Observed (black line) and calculated (red line mostly hidden by the black line) X-ray powder diffraction profile for the LeBail refinement. The bottom curve (blue line) is the difference plot on the same scale intensity and the tic marks (in green) are the calculated angles for the Bragg peaks in $2 \theta . \mathrm{b} /$ Comparison of experimental ${ }^{1} \mathrm{H}-{ }^{13} \mathrm{C}$ CPMAS NMR spectrum of the nanorods with the ${ }^{13} \mathrm{C}$ chemical shifts calculated by DFT, for models in which either $\mathrm{H}$ positions or all atomic positions were relaxed. It should be noted that for reasons of clarity of the figure, the ${ }^{13} \mathrm{C}$ resonances reported here (as verticle bars) were derived from the values found in Tables S2 and S3, by averaging the ${ }^{13} \mathrm{C}$ shifts of positions corresponding to chemically equivalent carbon atoms.

The structural model of the nanorods, derived from this multi-technique approach combining S-XRPD, multinuclear solid state NMR and DFT calculations, sheds light on the self-assembly process which takes place during the synthesis. The obtained asymmetric unit and the packing mode of $\mathbf{T} \mathbf{M P y} \mathbf{P}^{4+}$ and $\mathbf{B P h} \mathbf{4}^{-}$are represented in Figures 5a to 5c. As illustrated in Figure 5a, $\mathbf{T M P y} \mathbf{P}^{4+}$ self-assemble with $\mathbf{B P h} 4^{-}$to form columns of $\mathbf{T M P y} \mathbf{P}^{4+}$ along the $c$ crystallographic axis. The mean planes (based on least-square planes calculated for the 24 core atoms of the porphyrin core) of two successive porphyrins within these columns are separated by $\sim 11.6 \AA$ indicating that there is no $\pi$-overlap between them. As a consequence, the bathochromic shift of the absorption bands observed by UV-visible absorption spectroscopy (Fig. 1a) is not due to the aggregation of $\mathbf{T M P y P} \mathbf{P}^{\mathbf{4}}$, but may be attributed to the flattening of the porphyrin and the larger $\pi$ conjugation between the macrocycle and the meso pyridinium groups. In the absence of $\mathbf{B P h}_{4}{ }^{-}$, pyridinium groups are nearly perpendicular to the mean plane of the porphyrin core [28]. In the presence of $\mathbf{B P h}_{4}^{-}$within the nanorods, the four dihedral angles between the pyridinium groups and the mean plane of porphyrin 
core are $\sim 31.5^{\circ}, \sim 56.0^{\circ}, \sim 62.3^{\circ}$ and $\sim 63.7$, clearly indicating that the porphyrin is flattened and that $\pi$-conjugation between the porphyrin core and the meso pyridinium groups is increased. Therefore, the proposed structural model is in good agreement with theoretical calculations showing a dihedral angle of $\sim 60^{\circ}$ which induces a $\sim 30 \mathrm{~nm}$ bathochromic shift in the Soret absorption band of $\mathbf{T} \mathbf{M P y P} \mathbf{P}^{4+}$ [28]. We presume that a similar packing between $\mathbf{T} \mathbf{M P y} \mathbf{P}^{4+}$ and $\mathbf{B P h} 4^{-}$ takes place within previously reported nanoparticles of porphyrin without self-aggregation [20,21].
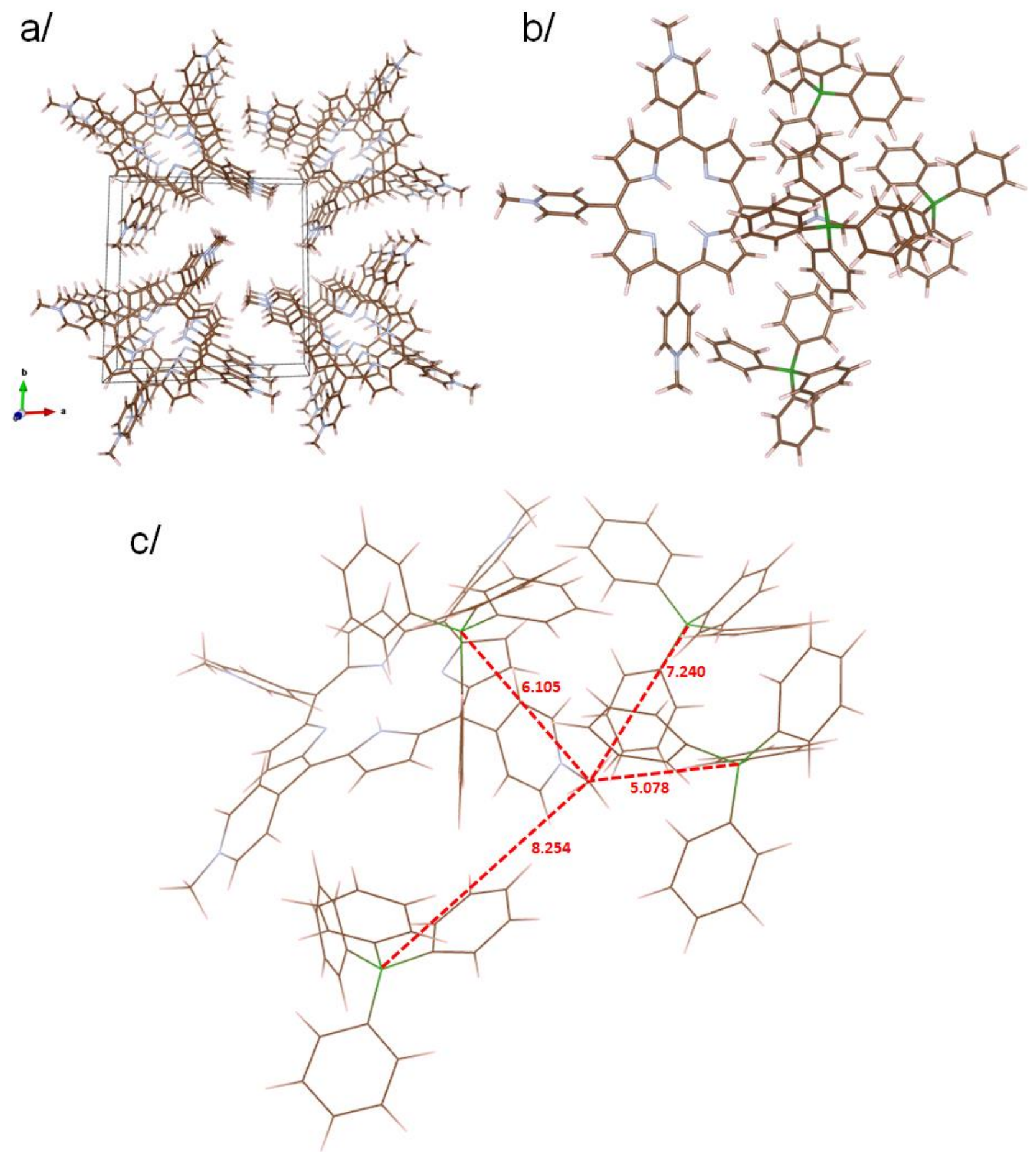

Fig. 5. a/ View of the packing of $\mathbf{T M P y P}^{4+}$ along the $c$ crystallographic axis (BPh $4^{-}$omitted for clarity). b/ Representation of the assymetric unit. c/ Representation of the coordination of the meso 4-N-methylpyridyl group / $\mathrm{BPh}_{4}^{-}$showing the $\mathrm{B}---\mathrm{C}(\mathrm{Me})$ distances (dashed red lines, distances in $\AA$ ).

Regarding cation/anion associations, each of the positively-charged meso 4-N-methylpyridyl groups of TMPyP ${ }^{4+}$ was found to be surrounded by four $\mathbf{B P h}_{4^{-}}$anions, according to the following layout (Figures $5 \mathrm{~b}$ and $5 \mathrm{c}$ ): (i) one $\mathbf{B P h}_{4}^{-}$ 
anion is aligned with the meso 4-N-methylpyridyl group with a $\mathrm{B}---\mathrm{C}(\mathrm{Me})$ distance close to $5.1 \AA^{\AA}$, (ii) two $\mathbf{B P h}_{4}^{-}$ anions are nested between two meso 4-N-methylpyridyl group with B---C(Me) distances between $\sim 7.3-8.3 \AA$ and (iii) the last $\mathbf{B P h}_{4}{ }^{-}$anion is located above the meso 4-N-methylpyridyl group (with a B---C(Me) distance $\sim 6.1 \AA$ ). It is worth noting that the B---H(Me) and B---H(NH) distances are in line with ${ }^{1} \mathrm{H}^{-11} \mathrm{~B}$ correlations observed by solid state NMR spectroscopy (Figure 3), because the shortest B---H(Me) and B---H(NH) are 4.3 and $7.9 \AA$, respectively. This explains why a longer contact time was needed in ${ }^{1} \mathrm{H} \rightarrow{ }^{11} \mathrm{~B}$ CPMAS to observe a cross-peak between $\mathrm{B}$ and $\mathrm{NH}$ signals compared to $\mathrm{B}$ and $\mathrm{CH}_{3}$ signals.

\section{CONCLUSION}

In this article, we have been able to synthesize and determine the structure of porphyrin nanorods, which are formed by self-assembly of two organic ions, namely free base meso 5,10,15,20-tetrakis-(4-N-methylpyridinium)porphyrin cations $\left(\mathbf{T M P y} \mathbf{P}^{\mathbf{4}}\right)$ and tetraphenylborate anions $\left(\mathbf{B P h}_{4}^{-}\right)$. The use of a combined experimental-computational approach, combining high-resolution synchrotron X-ray powder diffraction, multinuclear solid state NMR, and DFT calculations (including ab initio calculations of NMR parameters) was found to be critical to derive the structural model of these nano-objects. We expect similar "NMR-crystallography" types of strategies to be more commonly used in the future for the study of other porphyrin-based nano-objects.

\section{EXPERIMENTAL PART}

\section{Materials \& general methods}

Free base meso-tetrakis(4-pyridyl)porphyrin was synthesized from pyrrole and 4-pyridylcarboxyaldehyde via the method of Adler et al. [29]. Alkylation of free base meso-tetrakis(4-pyridyl)porphyrin with iodomethane was performed via reported procedure to obtain $\mathbf{T M P y P I}_{4}$ [30]. $\mathrm{NaBPh}_{4}$ was purchased from Aldrich and used as received. Samples for transmission electron microscopy (TEM) measurements were prepared by deposition of a drop of nanorod suspension in EtOH on a copper grid. TEM measurements were carried out at $100 \mathrm{kV}$ using a JEOL 1200 EXII microscope. Scanning electron microscopy measurements (SEM) were conducted on a Hitachi S4800 instrument. Powdered samples were simply deposited on double face tape and then Pt-metallized by sputtering under vacuum. The surface morphology of the samples was characterized by Atomic Force Microscopy (AFM) (NanoScope V, Bruker) in tapping mode using a commercial silicon probe (resonant frequency $\sim 300 \mathrm{kHz}$ and spring constant $\sim 20 \mathrm{~N} / \mathrm{m}$ ) in ambient conditions. UV-visible absorption spectra were recorded on a PerkinElmer Lambda 35 spectrophotometer in $10 \mathrm{~mm}$ quartz cells in water.

\section{Preparation of porphyrin nanorods.}

Stock solutions of TMPyP.I 4 (18 mg) in water $(50 \mathrm{~mL}$, concentration $0.3 \mathrm{mM})$ and $\mathbf{N a B P h}_{4}(22.5 \mathrm{mg})$ in water $(50$ $\mathrm{mL}$, concentration $1.2 \mathrm{mM}$ ) were first prepared. Then, four identical solutions were prepared by mixing absolute ethanol $(30 \mathrm{~mL})$, water $(2 \mathrm{~mL})$, and the stock solution of $\mathbf{N a B P h}_{4}(4 \mathrm{~mL})$, and placed in a thermostated bath at $30^{\circ} \mathrm{C}$ for one hour. Then, the stock solution of TMPyPI $(4 \mathrm{~mL})$ was added in the four reaction mixtures (final concentrations of TMPyPI 4 and $\mathbf{N a B P h}_{4}$ were 0.03 and $0.12 \mathrm{mM}$, respectively in $\mathrm{EtOH} / \mathrm{H}_{2} \mathrm{O} 3: 1$ ). After 24 hours of vigorous stirring at $30^{\circ} \mathrm{C}$ in the dark, the obtained brown solids contained in each reactor were filtered together (millipore, $022 \mu \mathrm{m}$ pore size). Then, they were dispersed in absolute ethanol and centrifugated at $20000 \mathrm{rpm}$ for 10 minutes before removing the supernatant (this step was repeated two times). Finally, porphyrin nanofibers were filtered (millipore, $022 \mu \mathrm{m}$ pore 
size), washed with absolute ethanol and dried under vacuum. Yield: $3.7 \mathrm{mg}$. The synthesis of porphyrin nanorods was repeated several times to obtain up to $\sim 20 \mathrm{mg}$ of porphyrin nanorods.

\section{Solid state NMR analyses.}

Solid state NMR experiments were performed at 14.1 T using a VNMRS-600 MHz instrument equipped with a $1.6 \mathrm{~mm}$ triple resonance probe, spinning at 30 to $40 \mathrm{kHz} .{ }^{1} \mathrm{H}$ MAS (magic angle spinning) NMR spectra were acquired spinning at $40 \mathrm{kHz}$, using a one pulse sequence with probe-background suppression by DEPTH. The ${ }^{1} \mathrm{H} 90^{\circ}$ excitation pulse was set to $2.5 \mu \mathrm{s}$. Recycle delays between 2 and $200 \mathrm{~s}$ were used, depending on the sample, and 16 scans were acquired. ${ }^{11} \mathrm{~B}$ MAS NMR experiments were conducted spinning at $40 \mathrm{kHz}$, using a $1.5 \mu \mathrm{s}{ }^{11} \mathrm{~B}$ excitation pulse, and spinal-64 ${ }^{1} \mathrm{H}$ decoupling (100 kHz RF) during acquisition. The recycle delay was set to $12 \mathrm{~s}$, and 12 scans wee acquired for each sample. Two-dimensional ${ }^{1} \mathrm{H} \rightarrow{ }^{11} \mathrm{~B}$ CPMAS experiments were performed spinning at $40 \mathrm{kHz}$, using a $2.5 \mu \mathrm{s}{ }^{1} \mathrm{H}$ excitation pulse, followed by contact times of 4 or $8 \mathrm{~ms}$, and applying spinal-64 ${ }^{1} \mathrm{H}$ decoupling during acquisition. The recycle delay was set to $3.5 \mathrm{~s}$, and up to 200 transients were acquired for each of the 4 (or 8 ) increments of the $2 \mathrm{D}$. The ${ }^{1} \mathrm{H} \rightarrow{ }^{13} \mathrm{C}$ CPMAS NMR experiments were performed spinning at $30 \mathrm{kHz}$, using a $2.5 \mu \mathrm{s}{ }^{1} \mathrm{H}$ excitation pulse, followed by a $2.5 \mathrm{~ms}$ contact time, and applying spinal-64 ${ }^{1} \mathrm{H}$ decoupling during acquisition. The recycle delay was set between 3 to $16 \mathrm{~s}$, depending on the sample, and the number of transients acquired ranged from 20 to $3500 .{ }^{1} \mathrm{H},{ }^{13} \mathrm{C}$ and ${ }^{11} \mathrm{~B}$ chemical shifts were referenced externally to adamantane $\left({ }^{1} \mathrm{H}\right.$ shift at $1.8 \mathrm{ppm}$ and high-frequency ${ }^{13} \mathrm{C}$ shift at 38.5 ppm), and $\mathrm{NaBH}_{4}\left({ }^{11} \mathrm{~B}\right.$ shift at $\left.-42.05 \mathrm{ppm}\right)$.

\section{High-resolution synchrotron X-ray powder diffraction}

High-resolution synchrotron X-ray powder diffraction (S-XRPD) data were collected at the Soleil synchrotron Soleil (Saint-Aubin, France) on the CRISTAL beamline, using the two 2-circle diffractometer in parallel beam Debye-Scherrer geometry with the $21 \mathrm{Si}(111)$ crystal multianalyzer stage [31]. The sample was previously loaded into a $0.7 \mathrm{~mm}$ glass capillary, and measurements were performed at $125 \mathrm{~K}$ and at room temperature using a wavelength $\lambda=$ $0.726466 \AA$ from $0^{\circ}$ to $40^{\circ}$, with a $0.002^{\circ}$ step. Examination of the XRPD patterns using the FoX (Free Objects for Crystallography) software [32] showed that the nanorods crystallize in the triclinic crystal system, space group P1, with the following unit cell parameters: $a \sim 16.611 \AA, b \sim 16.63633 \AA, c \sim 11.80891 \AA, \alpha \sim 110.79^{\circ}, \beta \sim 110.67^{\circ}, \gamma \sim 82.86^{\circ}$. Starting from the determined parameters, the unit cell parameters were determined for both temperatures using Lebail method using the Jana2006 software package [33]. The structural model was obtained by using FoX software considering a $\mathbf{T} \mathbf{M P y} \mathbf{P}^{4+} / \mathbf{B P h}_{4}^{-}$1:4 ratio. The initial structural model obtained by FoX was then optimized by DFT calculations.

\section{DFT calculations.}

The unit cell parameters were set to the X-ray diffraction parameters and kept fixed during geometry optimizations to ensure consistency between experimental and optimized structures. Protons were initially positioned to be consistent with the expected structure of the system and all atomic positions were then relaxed with the VASP (Vienna Ab-initio Simulation Package) code [34] based on the Kohn-Sham Density Functional Theory (DFT) and using a plane-wave pseudopotential approach. The NMR parameters were then calculated within Kohn-Sham DFT using the QUANTUMESPRESSO code [35-37], keeping the atomic positions equal to the values previously calculated with VASP. The PBE generalized gradient approximation [38] was used and the valence electrons were described by norm conserving pseudopotentials [39] in the Kleinman Bylander form [40]. The shielding tensor was computed using the Gauge Including Projector Augmented Wave (GIPAW) approach [41], which enables the reproduction of the results of a fully 
converged all electron calculation [42]. The isotropic chemical shift $\delta_{\text {iso }}$ is defined as $\delta_{\text {iso }}=-\left[\sigma-\sigma_{\text {ref }}\right]$ where $\sigma$ is the isotropic shielding and $\sigma_{\text {ref }}$ is the isotropic shielding of the same nucleus in a reference system. For ${ }^{1} \mathrm{H},{ }^{13} \mathrm{C}$ and ${ }^{11} \mathrm{~B}$, $\sigma_{\text {ref }}$ was fixed so that the average sum of experimental and calculated shifts of a series of reference compounds coincide

[43]. The principal components $V_{x x}, V_{y y}$, and $V_{z z}$ of the electric field gradient (EFG) tensor defined as $\left|V_{z z}\right| \geq\left|V_{x x}\right| \geq$ $\left|\mathrm{V}_{\mathrm{yy}}\right|$ are obtained by diagonalisation of the calculated tensor. The quadrupolar interaction can then be characterized by the quadrupolar coupling constant $\mathrm{C}_{\mathrm{Q}}$ and the asymmetry parameter $\eta_{\mathrm{Q}}$, which are defined as : $\mathrm{C}_{\mathrm{Q}}=\mathrm{eQV}_{\mathrm{zz}} / \mathrm{h}_{\mathrm{and}} \eta_{\mathrm{Q}}=$ $\left(\mathrm{V}_{\mathrm{yy}}-\mathrm{V}_{\mathrm{xx}}\right) / \mathrm{V}_{\mathrm{zz}}$ (e is the proton charge, $\mathrm{h}$ Planck's constant and $\mathrm{Q}$ the quadrupole moment of the considered nucleus). The $\mathrm{Q}$ values reported by Pyykkö were used in the calculations for ${ }^{11} \mathrm{~B}$ [44].

\section{Acknowledgements}

The synchrotron powder X-ray diffraction data was recorded on the CRISTAL beamline at Soleil at Gif-sur Yvette, France (proposal \#20140477). NMR spectroscopic calculations were performed using HPC resources from GENCIIDRIS (Grant 097535). Financial support from the University of Montpellier is greatly aknowledged.

\section{Supporting information}

Figures S1-S2 and Tables S1-S3 are given in the supplementary materials. This material is available free of charge via the Internet at http://www.worldscinet.com/jpp/jpp.shtml.crystallographic data have been deposited at the Cambridge Crystallographic Data Centre (CCDC) under number CCDC-1951234. Copies can be obtained on request, free of charge, via http://www/ccdc.cam..ac;uk/data \request/cif or from the Cambridge Crystallographic Data Centre, 12 Union Road, Cambridge CB2 1EZ, UK (fax +441223-336-033 or email: deposit@ccdc.cam.ac.uk).

\section{REFERENCES}

1. Frigaard, NU, Chew AGM, Li H, Maresca JA and Bryant DA, Photosynth. Res. 2003; 78 93-117.

2. Montano, GA, Bowen BP, LaBelle JT, Woodbury NW, Pizziconi VB and Blankenship R,. Biophys. J. 2003; 85, $2560-2565$.

3. Wagner RW and Lindsey JS, J. Am. Chem. Soc. 1994; 116, 9759-9760.

4. Senge MO, Fazekas, M, Notaras EGA, Blau WJ, Zawadzka M, Locos OB and Ni Mhuircheartaigh EM, Adv. Mater. 2007; 19, 2737-2774.

5. Walter MG, Rudine AB and Wamser CC, J. Porphyrins Phthalocyanines 2010; 14, 759-792.

6. Fukuzumi S and Ohkubo K, J.Mater.Chem. 2012; 22, 4575-458.

7. $\quad$ Cen TY, Whang SP, Zhang Z, Wu J and Li S, J. Porphyrins Phthalocyanines 2018; 22, 726-738.

8. Gong X, Milic T, Xu C, Batteas JD and Drain CM, J. Am. Chem. Soc. 2002; 124, 14290-14291.

9. Wang D, Niu, L, Qiao Z-Y, Cheng D-B, Wang J, Zhong Y, Bai F, Wang H and Fan H, ACS Nano 201;: 12, 37963803.

10. Schwab AD, Smith DE, Rich CS, Young ER, Smith WF and de Paula JC, J. Phys. Chem. B 2003; 107, 1133911345 .

11. Mongwaketsi N, Mayedwa N, Matinise N, Kaviyarasu K, Sparrow R and Maaza M, J. Porphyrins Phthtalocyanines 2018; 22, 303-317.

12. Wang Z, Ho KJ, Medforth CJ and Shelnutt JA, Adv. Mater. 2006; 18, 2557-2560.

13. Wang Z, Medforth CJ and Shelnutt JA, J. Am. Chem. Soc. 2004; 126, 1954-15955.

14. Medforth CJ, Wang Z, Martin KE, Song Y, Jacobsen JL and Shelnutt JA, Chem. Commun. 2009; 7261-7277 
15. Maiti NC, Mazumdar S and Periasamy N, J. Phys. Chem. B 1998; 102, 1528-1538.

16. Wang L, Chen Y and Jiang J, Nanoscale 2014; 6, 1871-1878.

17. Rananaware A, Bhosale RS, Ohkubo K, Patil H, Jones LA, Jasckon SL, Fukuzumi S, Bhosale SV and Bhosale SV, J. Org. Chem. 2015; 80, 3832-3840.

18. Zhang N, Wang L, Wang H, Cao R, Wang J, Bai F and Fan H, Nano Lett. 2018: 18, 560-566

19. Mauriello Jimenez C, Aggad D, Croissant JG, Tresfield K, Laurencin D, Berthomieu D, Cubedo N, Rossel M, Alsaiari S, Anjum DH, Sougrat R, Roldan-Gutierrez MA, Richeter S, Oliviero E, Raehm L, Charnay C, Cattoën X, Clément S, Wong Chi Man M, Maynadier M, Chaleix V, Sol V, Garcia M, Gary-Bobo M, Khashab NM, Bettache N and Durand J-O, Adv. Funct. Mat. 2018; 1800235.

20. Ou Z-M, Yao H and Kimura K, Chem. Lett. 2006: 35, 782-783.

21. Ou Z-M, Yao H and Kimura K, Photochem.Photobiol.A 2007; 189, 7-14.

22. Garcia-Sampedro A, Tabero A, Mahamed I and Acedo P, J. Porphyrins Phthalocyanines 2019: 23, 11-27.

23. Cenklova V, Photochem. Photobiol. B 2017; 173, 522-537.

24. Shi DF, Wheelhouse RT, Sun D and Hurley LH, J. Med. Chem. 2001; 44, 4509-4523.

25. Freyer MW, Buscaglia R, Kaplan K, Cashman D and Hurley LH, Lewis EA, Biophys. J. 2007; 92, $2007-2015$.

26. Guo K, Pourpak A, Beetz-Rogers K, Gokhale V, Sun D and Hurley LH, J. Am. Chem. Soc. 2007; 129, 1022010228.

27. Siddiqui-Jain A, Grand CL, Bearss DJ and Hurley LH, Proc. Natl. Acad. Sci. U. S. A. 2002; 99, 11593-11598.

28. Chernia Z and Gill D, Langmuir 1999; 15, 1625-1633.

29. Adler AD, Longo FR, Finarelli JD, Goldmacher J, Assour J and Korsakoff L, J. Org. Chem.1967; 32, 467.

30. Monteiro AR, Ramos CIV, Fateixa S, Moura NMM, Neves MGPMS and Trindade T, ACS Omega, 2018; 3, 11184-11191.

31. Hodeau J-L, Bordet P, Anne M, Prat A, Fitch AN, Dooryhee E, Vaughan G and Freund AK, Proc. SPIE 1998; 3448, 353-361.

32. Favre-Nicolin V and Cerny R, J. Appl. Cryst. 2002; 35, 734-743.

33. Petříček V, Dušek M and Palatinus L, Z. Kristallogr. 2014; 229, 345-352.

34. Kresse G and Hafner J, Phys. Rev. B 1994; 49, 14251-14269.

35. Giannozzi P, Baroni S, Bonini N, Calandra M, Car R, Cavazzoni C, Ceresoli D, Chiarotti GL, Cococcioni M, Dabo I, Dal Corso A, de Gironcoli S, Fabris S, Fratesi G, Gebauer R, Gerstmann U, Gougoussis C, Kokalj A, Lazzeri M, Martin-Samos L, Marzari N, Mauri F, Mazzarello R, Paolini S, Pasquarello A, Paulatto L, Sbraccia C, Scandolo S, Sclauzero G, Seitsonen AP, Smogunov A, Umari P and Wentzcovitch RM, J. Phys. Cond. Matt. $2009 ; 21,395502$.

36. http://www.pwscf.org.

37. Baroni S, de Gironcoli S, Dal Corso A and Giannozzi P, Rev. Mod. Phys. 2001; 73, 515-562.

38. Perdew JP, Burke K and Ernzerhof M, Phys. Rev. Lett. 1996; 77, 3865-3868.

39. Troullier N and Martins JL, Phys. Rev. B 1991; 43, 1993-2006.

40. Kleinman L and Bylander D, Phys. Rev. Lett. 1982; 48, 1425-1428.

41. Pickard C and Mauri F, Phys. Rev. B 2001; 63, 245101.

42. Lejaeghere K, Bihlmayer G, Björkman T, Blaha P, Blügel S, Blum V, Caliste D, Castelli IE, Clark SJ, Dal Corso A, de Gironcoli S, Deutsch T, Dewhurst JK, Di Marco I, Draxl C, Dułak M, Eriksson O, Flores-Livas JA, Garrity KF, Genovese L, Giannozzi P, Giantomassi M, Goedecker S, Gonze X, Grånäs O, Gross EKU, Gulans A, Gygi F, Hamann DR, Hasnip PJ, Holzwarth NAW, Iuşan D, Jochym DB, Jollet F, Jones D, Kresse G, Koepernik K, 
Küçükbenli E, Kvashnin YO, Locht ILM, Lubeck S, Marsman M, Marzari N, Nitzsche U, Nordström L, Ozaki T, Paulatto L, Pickard CJ, Poelmans W, Probert MIJ, Refson K, Richter M, Rignanese GM, Saha S, Scheffler M, Schlipf M, Schwarz K, Sharma S, Tavazza F, Thunström P, Tkatchenko A, Torrent M, Vanderbilt D, van Setten MJ, van Speybroeck V, Wills JM, Yates JR, Zhang GU and Cottenier S, Science 2016; 351, 1415-1423.

43. Berthomieu D, Gervais C, Renaudin G, Reinholdt M, Sene S, Smith ME, Bonhomme C and Laurencin D, Eur. J. Inorg. Chem. 2015; 1182-1191.

44. Pyykkö P, Mol. Phys. 2008; 106, 1965-1974. 


\section{Synthesis, characterization and modeling of self-assembled porphyrin nanorods}

Danielle Laurencin, Pascal G. Yot, Christel Gervais, Yannick Guari, Sébastien Clément, Erik Elkaim, Matthieu Paillet, Didier Cot, Sébastien Richeter

Porphyrin nanorods prepared by "ion-association" method were characterized at the molecular level by combining different techniques including multinuclear solid state NMR spectroscopy, synchrotron X-ray powder diffraction and DFT calculations.

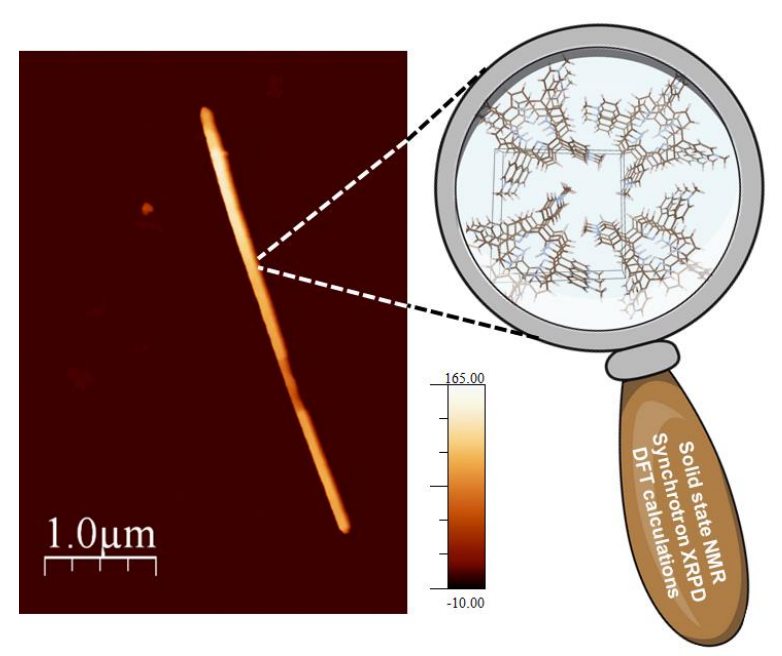




\title{
Synthesis, characterization and modeling of self-assembled porphyrin nanorods
}

\author{
Danielle Laurencin ${ }^{a}$, Pascal Yot ${ }^{a}$, Christel Gervais ${ }^{b}, Y^{2}$ nick Guaria, Sébastien \\ Clément $^{\mathrm{a}}$, Erik Elkaim ${ }^{\mathrm{c}}$, Matthieu Paillet ${ }^{\mathrm{d}}$, Didier $\operatorname{Cot}^{\mathrm{e}}$ and Sébastien Richeter ${ }^{\star a}$ \\ a Institut Charles Gerhardt de Montpellier, ICGM, UMR 5253, CNRS UM ENSCM, 34095 Montpellier, France \\ b Laboratoire de Chimie de la Matière Condensée de Paris, LCMCP, UMR 7574, Sorbonne Université, Collège de France, 75005 Paris, \\ France \\ c Synchrotron SOLEIL, L'Orme des Merisiers Saint-Aubin, BP 48, 91192 Gif-sur-Yvette, France \\ d Laboratoire Charles Coulomb, L2C, UMR 5221, CNRS UM, 34095 Montpellier, France \\ e Institut Européen des Membranes, IEM, UMR 5635, Université Montpellier, ENSCM, CNRS, 34095 Montpellier, France
}

\section{SUPPORTING INFORMATION}

Figure S1. 2D ${ }^{1} \mathrm{H} \rightarrow{ }^{13} \mathrm{C}$ CPMAS spectrum of the nanorods.

Figure S2. Structure-independent refinement of the unit-cell of the diffraction pattern obtained for the nanorods at room temperature.

Table S1. Unit cell parameters, unit cell volume, space group and factors of agreement obtained for the nanorods, for the two considered temperatures.

Table S2. GIPAW-DFT calculated $\delta_{\text {iso }}$ (in ppm), $C_{Q}$ (in MHz) and $\eta$ NMR parameters for ${ }^{11} \mathrm{~B},{ }^{13} \mathrm{C}$ and ${ }^{1} \mathrm{H}$, in the "Rel-H" model of the nanorods.

Table S3. GIPAW-DFT calculated $\delta_{\text {iso }}$ (in ppm), $\mathrm{C}_{\mathrm{Q}}$ (in MHz) and $\eta \mathrm{NMR}$ parameters for ${ }^{11} \mathrm{~B},{ }^{13} \mathrm{C}$ and ${ }^{1} \mathrm{H}$, in the "Rel-tot" model of the nanorods. 


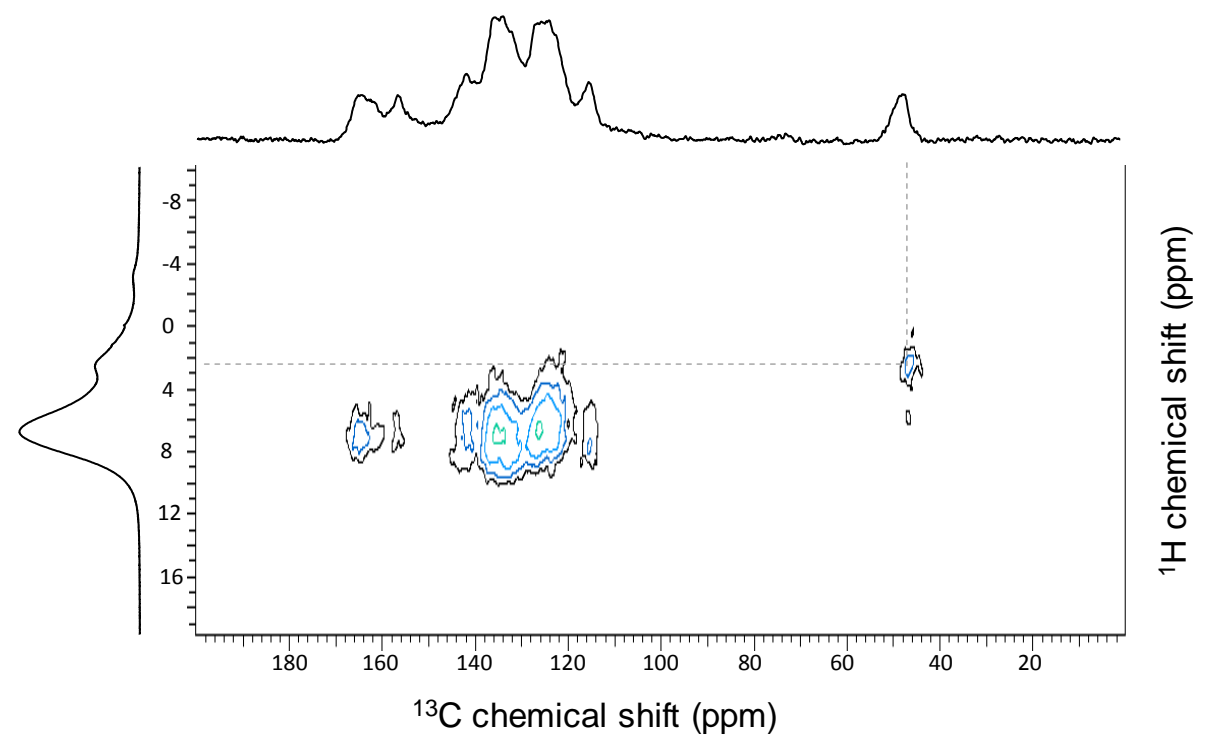

Figure S1. 2D ${ }^{1} \mathrm{H} \rightarrow{ }^{13} \mathrm{C}$ CPMAS spectrum of the nanorods, confirming the assignment of the ${ }^{1} \mathrm{H}$ resonance centered at $\sim 2 \mathrm{ppm}$ to methyl group protons. The spectrum was recorded at $14.1 \mathrm{~T}$, spinning at $30 \mathrm{kHz}$, with a contact time of $2 \mathrm{~ms}$, and spinal-64 ${ }^{1} \mathrm{H}$ decoupling during acquisition. The projections shown along both axes correspond to the $1 \mathrm{D}^{1} \mathrm{H}$ MAS and ${ }^{13} \mathrm{C}$ CPMAS NMR spectra.

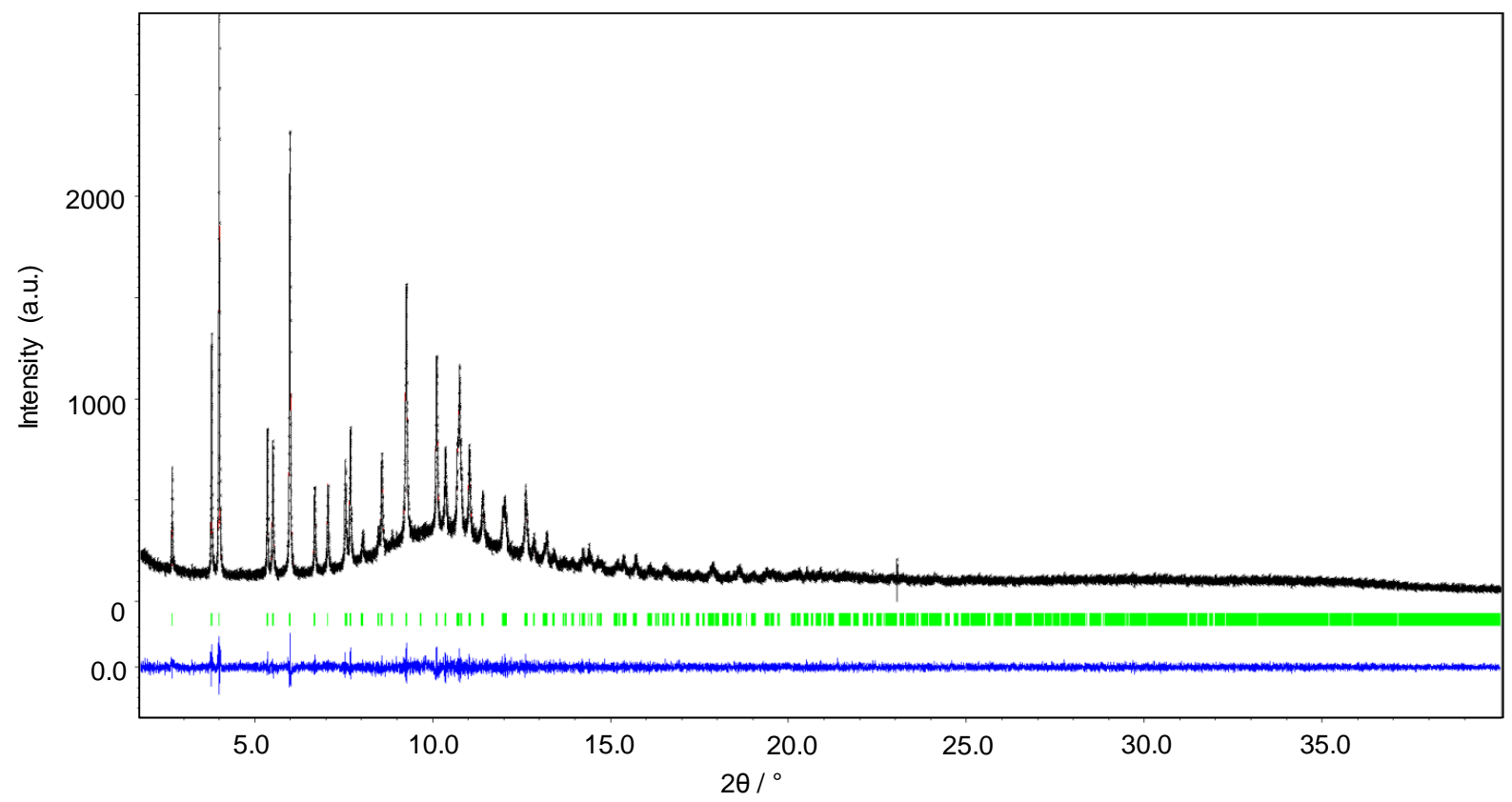

Figure S2. Structure-independent refinement of the unit-cell of the diffraction pattern obtained for the nanorods at room temperature. Observed (black line) and calculated (red line) X-ray powder diffraction profile for the LeBail refinement. The bottom curve (in blue) is the difference plot on the same scale intensity and the bars (in green) are the calculated angles for the Bragg peaks in $2 \theta$. 
Table S1. Unit cell parameters, unit cell volume, space group and factors of agreement obtained for the nanorods, for the two considered temperatures.

\begin{tabular}{|c|c|c|}
\hline Temperature & $125 \mathrm{~K}$ & Room temperature \\
\hline Formula & \multicolumn{2}{|c|}{$\mathrm{B}_{4} \mathrm{C}_{140} \mathrm{H}_{118} \mathrm{~N}_{8}$} \\
\hline Molar mass (g.mol-1) & \multicolumn{2}{|c|}{1955.78} \\
\hline Space Group & \multicolumn{2}{|c|}{ P1 (No. 1) } \\
\hline $\mathrm{Z}$ & \multicolumn{2}{|c|}{1} \\
\hline a (Å) & $16.563(2)$ & $16.611(1)$ \\
\hline b (Å) & $16.5729(6)$ & $16.636(2)$ \\
\hline$c(\AA)$ & $11.6236(2)$ & $11.8089(3)$ \\
\hline$\alpha\left({ }^{\circ}\right)$ & $110.636(3)$ & $110.79(1)$ \\
\hline$\beta\left(^{\circ}\right)$ & $110.54(2)$ & $110.672(4)$ \\
\hline$\gamma\left({ }^{\circ}\right)$ & $82.95(1)$ & $82.860(8)$ \\
\hline Vol. $\left(\AA^{3}\right)$ & $2796.2(1)$ & $2858.0(1)$ \\
\hline density & 1.1615 & 1.1378 \\
\hline GoF & 1.04 & 0.91 \\
\hline Rp & 2.85 & 5.53 \\
\hline wRp & 3.75 & 7.17 \\
\hline
\end{tabular}


Table S2. GIPAW-DFT calculated $\delta_{\text {iso }}$ (in ppm), $C_{Q}$ (in MHz) and $\eta$ NMR parameters for ${ }^{11} B,{ }^{13} \mathrm{C}$ and ${ }^{1} \mathrm{H}$, in the "Rel-H" model of the nanorods (in which only $\mathrm{H}$ atom positions are relaxed).

$\begin{array}{lrrr} & \delta_{\text {iso }} & \mathrm{C}_{\mathrm{Q}} & \eta \\ \text { B1 } & -13.9 & -0.28 & 0.14 \\ \text { B2 } & -8.6 & 0.26 & 0.67 \\ \text { B3 } & -9.8 & 0.21 & 0.93 \\ \text { B4 } & -5.0 & -0.13 & 0.35\end{array}$

\begin{tabular}{|c|c|c|c|}
\hline & $\delta_{\text {iso }}$ & & $\delta_{\text {iso }}$ \\
\hline C1 & 175.5 & H1 & 6.6 \\
\hline C2 & 152.1 & $\mathrm{H} 2$ & 4.7 \\
\hline C3 & 134.0 & H3 & 5.7 \\
\hline C4 & 124.6 & H4 & 6.6 \\
\hline C5 & 133.2 & H5 & 5.4 \\
\hline C6 & 141.1 & H6 & 8.0 \\
\hline C7 & 177.4 & H7 & 9.3 \\
\hline C8 & 144.2 & H8 & 7.9 \\
\hline C9 & 130.2 & H9 & 7.1 \\
\hline C10 & 128.8 & H10 & 8.3 \\
\hline C11 & 171.8 & H11 & 6.6 \\
\hline C12 & 150.9 & H12 & 6.0 \\
\hline C13 & 137.5 & H13 & 8.0 \\
\hline C14 & 124.5 & H14 & 7.1 \\
\hline C15 & 173.2 & H15 & 6.4 \\
\hline C16 & 143.9 & H16 & 4.9 \\
\hline C17 & 134.6 & H17 & 4.4 \\
\hline C18 & 127.4 & H18 & 8.1 \\
\hline C19 & 132.8 & H19 & 13.2 \\
\hline C20 & 140.9 & $\mathrm{H} 2 \mathrm{O}$ & 7.0 \\
\hline C21 & 144.0 & H21 & 4.6 \\
\hline C22 & 126.6 & H22 & 5.5 \\
\hline C23 & 136.2 & H23 & 10.2 \\
\hline C24 & 126.1 & H24 & 6.7 \\
\hline C25 & 157.6 & H25 & 7.2 \\
\hline C26 & 109.4 & H26 & 6.5 \\
\hline C27 & 120.4 & H27 & 6.0 \\
\hline C28 & 136.7 & H28 & 9.0 \\
\hline C29 & 161.0 & H29 & 8.4 \\
\hline C30 & 132.0 & H30 & 7.1 \\
\hline C31 & 152.4 & H31 & 7.2 \\
\hline C32 & 167.1 & H32 & 7.5 \\
\hline C33 & 165.3 & H33 & 6.2 \\
\hline C34 & 128.2 & H34 & 7.7 \\
\hline C35 & 131.2 & H35 & 3.5 \\
\hline
\end{tabular}




\begin{tabular}{|c|c|c|c|}
\hline C36 & 167.9 & H36 & 8.8 \\
\hline C37 & 140.1 & H37 & 7.7 \\
\hline C38 & 117.6 & H38 & 5.6 \\
\hline C39 & 126.9 & H39 & 4.3 \\
\hline C40 & 145.8 & H40 & 8.8 \\
\hline C41 & 126.7 & H41 & 7.4 \\
\hline C42 & 161.0 & H42 & 9.0 \\
\hline C43 & 138.1 & H43 & 8.3 \\
\hline C44 & 148.8 & H44 & 9.6 \\
\hline C45 & 134.3 & H45 & 6.9 \\
\hline C46 & 148.3 & H46 & 9.8 \\
\hline C47 & 141.1 & H47 & 7.7 \\
\hline C48 & 137.8 & H48 & 7.4 \\
\hline C49 & 164.7 & H49 & 7.4 \\
\hline C50 & 145.0 & H50 & 5.5 \\
\hline C51 & 145.3 & H51 & 9.8 \\
\hline C52 & 153.9 & H52 & 7.2 \\
\hline C53 & 130.0 & H53 & 5.1 \\
\hline C54 & 153.8 & H54 & 7.4 \\
\hline C55 & 144.2 & H55 & 6.9 \\
\hline C56 & 133.6 & H56 & 5.6 \\
\hline C57 & 147.4 & H57 & 7.5 \\
\hline C58 & 147.4 & H58 & 10.1 \\
\hline C59 & 143.9 & H59 & 7.6 \\
\hline C60 & 174.1 & H6O & 6.3 \\
\hline C61 & 126.6 & H61 & 4.7 \\
\hline C62 & 137.0 & H62 & 5.4 \\
\hline C63 & 159.2 & H63 & 1.4 \\
\hline C64 & 150.4 & H64 & 4.8 \\
\hline C65 & 41.4 & H65 & 2.7 \\
\hline C66 & 53.1 & H66 & 2.6 \\
\hline C67 & 42.4 & H67 & 2.0 \\
\hline C68 & 44.3 & H68 & 7.2 \\
\hline C69 & 168.8 & H69 & 2.5 \\
\hline C70 & 150.0 & H70 & 2.5 \\
\hline C71 & 127.6 & H71 & 2.0 \\
\hline C72 & 126.6 & H72 & 6.5 \\
\hline C73 & 130.3 & H73 & 10.0 \\
\hline C74 & 142.1 & H74 & 3.2 \\
\hline C75 & 177.3 & H75 & 1.7 \\
\hline C76 & 137.5 & H76 & 4.2 \\
\hline C77 & 127.1 & H77 & 5.8 \\
\hline C78 & 130.7 & H78 & 10.1 \\
\hline C79 & 181.3 & H79 & 6.0 \\
\hline C80 & 139.8 & H80 & 4.1 \\
\hline C81 & 156.9 & H81 & 4.1 \\
\hline
\end{tabular}




\begin{tabular}{|c|c|c|c|}
\hline C82 & 119.8 & H82 & 5.6 \\
\hline C83 & 181.0 & H83 & 7.1 \\
\hline C84 & 141.0 & H84 & 9.6 \\
\hline C85 & 130.2 & H85 & 8.7 \\
\hline C86 & 124.3 & H86 & 9.7 \\
\hline C87 & 134.1 & H87 & 3.9 \\
\hline C88 & 139.3 & H88 & 4.9 \\
\hline C89 & 146.7 & H89 & 6.2 \\
\hline C90 & 134.6 & H9O & 4.8 \\
\hline C91 & 142.5 & H91 & 6.8 \\
\hline C92 & 126.8 & H92 & 5.9 \\
\hline C93 & 196.0 & H93 & 7.7 \\
\hline C94 & 146.0 & H94 & 6.4 \\
\hline C95 & 128.3 & H95 & 4.9 \\
\hline C96 & 131.8 & H96 & 6.6 \\
\hline C97 & 129.0 & H97 & 6.3 \\
\hline C98 & 132.3 & H98 & 7.1 \\
\hline C99 & 177.6 & H99 & 7.4 \\
\hline C100 & 145.9 & H100 & 8.0 \\
\hline C101 & 128.1 & H101 & 3.9 \\
\hline C102 & 129.2 & H102 & 10.5 \\
\hline C103 & 174.4 & H103 & 5.8 \\
\hline C104 & 146.7 & H104 & 6.8 \\
\hline C105 & 130.4 & H105 & 5.5 \\
\hline C106 & 132.2 & H106 & 4.4 \\
\hline C107 & 167.9 & H107 & 10.0 \\
\hline C108 & 130.2 & H108 & 11.0 \\
\hline C109 & 134.6 & H109 & 8.4 \\
\hline C110 & 131.7 & H110 & 6.8 \\
\hline C111 & 132.8 & H111 & 0.9 \\
\hline C112 & 141.6 & H112 & 3.2 \\
\hline C113 & 150.1 & H113 & 6.3 \\
\hline C114 & 128.4 & H114 & 7.9 \\
\hline C115 & 139.1 & H115 & 4.5 \\
\hline C116 & 123.7 & H116 & 8.0 \\
\hline C117 & 170.7 & H117 & 7.6 \\
\hline C118 & 136.6 & H118 & 7.0 \\
\hline C119 & 138.8 & & \\
\hline C120 & 121.0 & & \\
\hline C121 & 124.9 & & \\
\hline C122 & 138.5 & & \\
\hline C123 & 194.0 & & \\
\hline C124 & 150.5 & & \\
\hline C125 & 127.7 & & \\
\hline C126 & 125.6 & & \\
\hline C127 & 181.3 & & \\
\hline
\end{tabular}




$\begin{array}{ll}\text { C128 } & 144.7 \\ \text { C129 } & 127.0 \\ \text { C130 } & 139.8 \\ \text { C131 } & 182.2 \\ \text { C132 } & 139.7 \\ \text { C133 } & 129.5 \\ \text { C134 } & 135.2 \\ \text { C135 } & 132.7 \\ \text { C136 } & 139.3 \\ \text { C137 } & 140.1 \\ \text { C138 } & 136.3 \\ \text { C139 } & 142.0 \\ \text { C140 } & 137.1\end{array}$


Table S3. GIPAW-DFT calculated $\delta_{\text {iso }}$ (in ppm), $\mathrm{C}_{\mathrm{Q}}$ (in MHz) and $\eta \mathrm{NMR}$ parameters for ${ }^{11} \mathrm{~B},{ }^{13} \mathrm{C}$ and ${ }^{1} \mathrm{H}$, in the "Rel-tot" model of the nanorods (in which all atom positions are relaxed).

$\begin{array}{lrrr} & \delta_{\text {iso }} & C_{Q} & \eta \\ \text { B1 } & -6.9 & -0.25 & 0.43 \\ \text { B2 } & -9.9 & 0.38 & 0.16 \\ \text { B3 } & -6.2 & 0.46 & 0.26 \\ \text { B4 } & -8.4 & 0.11 & 0.42\end{array}$

\begin{tabular}{|c|c|c|c|}
\hline & $\delta_{\text {iso }}$ & & $\delta_{\text {iso }}$ \\
\hline C1 & 165.9 & H1 & 6.1 \\
\hline C2 & 140.5 & $\mathrm{H} 2$ & 7.2 \\
\hline C3 & 128.6 & H3 & 7.5 \\
\hline C4 & 126.0 & H4 & 7.3 \\
\hline C5 & 126.6 & H5 & 8.0 \\
\hline C6 & 141.0 & H6 & 8.3 \\
\hline C7 & 173.8 & H7 & 9.8 \\
\hline C8 & 143.4 & H8 & 5.6 \\
\hline C9 & 129.2 & $\mathrm{H} 9$ & 6.1 \\
\hline C10 & 124.4 & H10 & 8.2 \\
\hline C11 & 168.7 & H11 & 6.5 \\
\hline C12 & 141.9 & H12 & 6.2 \\
\hline C13 & 130.5 & H13 & 6.7 \\
\hline C14 & 123.7 & H14 & 3.1 \\
\hline C15 & 165.3 & H15 & 5.2 \\
\hline C16 & 138.6 & H16 & 3.6 \\
\hline C17 & 126.4 & H17 & 2.3 \\
\hline C18 & 127.7 & H18 & 6.3 \\
\hline C19 & 128.6 & H19 & 7.5 \\
\hline $\mathrm{C} 20$ & 134.5 & $\mathrm{H} 20$ & 5.4 \\
\hline C21 & 143.2 & H21 & 4.8 \\
\hline C22 & 123.8 & $\mathrm{H} 22$ & 2.9 \\
\hline C23 & 141.6 & H23 & 8.7 \\
\hline C24 & 129.1 & H24 & 7.6 \\
\hline C25 & 140.7 & H25 & 7.0 \\
\hline C26 & 130.6 & H26 & 6.3 \\
\hline C27 & 133.2 & H27 & 3.8 \\
\hline C28 & 137.2 & H28 & 4.2 \\
\hline$C 29$ & 154.5 & H29 & 6.1 \\
\hline C30 & 143.5 & H30 & 7.2 \\
\hline C31 & 141.7 & H31 & 7.1 \\
\hline C32 & 163.0 & H32 & 6.4 \\
\hline C33 & 160.9 & H33 & 7.0 \\
\hline C34 & 139.0 & H34 & 5.5 \\
\hline C35 & 139.4 & H35 & 4.1 \\
\hline
\end{tabular}




\begin{tabular}{|c|c|c|c|}
\hline C36 & 156.2 & H36 & 6.5 \\
\hline C37 & 142.8 & H37 & 6.1 \\
\hline C38 & 128.5 & H38 & 5.2 \\
\hline C39 & 138.7 & H39 & 2.3 \\
\hline C40 & 136.2 & H40 & 8.1 \\
\hline C41 & 120.6 & H41 & 3.7 \\
\hline C42 & 163.6 & H42 & 7.2 \\
\hline C43 & 139.9 & H43 & 8.4 \\
\hline C44 & 142.0 & H44 & 8.6 \\
\hline C45 & 137.6 & H45 & 7.5 \\
\hline C46 & 145.9 & H46 & 4.9 \\
\hline C47 & 120.2 & H47 & 6.5 \\
\hline C48 & 155.4 & H48 & 7.0 \\
\hline C49 & 148.1 & H49 & 6.5 \\
\hline C50 & 137.7 & H50 & 2.5 \\
\hline C51 & 138.1 & H51 & 7.6 \\
\hline C52 & 147.7 & H52 & 6.2 \\
\hline C53 & 124.5 & H53 & 6.1 \\
\hline C54 & 161.8 & H54 & 8.5 \\
\hline C55 & 133.7 & H55 & 5.9 \\
\hline C56 & 141.2 & H56 & 4.8 \\
\hline C57 & 141.0 & H57 & 6.7 \\
\hline C58 & 144.4 & H58 & 6.1 \\
\hline C59 & 122.3 & H59 & 7.2 \\
\hline C60 & 159.0 & H60 & 7.7 \\
\hline C61 & 139.6 & H61 & 5.2 \\
\hline C62 & 133.1 & H62 & 5.3 \\
\hline C63 & 148.9 & H63 & -1.9 \\
\hline C64 & 144.0 & H64 & 4.5 \\
\hline C65 & 45.2 & H65 & 3.8 \\
\hline C66 & 45.6 & H66 & 3.3 \\
\hline C67 & 46.4 & H67 & 2.2 \\
\hline C68 & 46.8 & H68 & 7.5 \\
\hline C69 & 167.0 & H69 & 2.5 \\
\hline C70 & 131.1 & H70 & 3.0 \\
\hline C71 & 126.7 & H71 & 1.6 \\
\hline C72 & 121.7 & H72 & 7.0 \\
\hline C73 & 126.3 & H73 & 8.6 \\
\hline C74 & 140.7 & H74 & 2.3 \\
\hline C75 & 178.8 & H75 & 0.4 \\
\hline C76 & 132.1 & H76 & 0.4 \\
\hline C77 & 129.6 & H77 & 4.4 \\
\hline C78 & 124.7 & H78 & 8.3 \\
\hline C79 & 184.0 & H79 & 6.2 \\
\hline C80 & 131.7 & H80 & 3.6 \\
\hline C81 & 128.8 & H81 & 3.5 \\
\hline
\end{tabular}




\begin{tabular}{|c|c|c|c|}
\hline C82 & 126.0 & H82 & 3.6 \\
\hline C83 & 169.0 & H83 & 5.7 \\
\hline C84 & 139.1 & H84 & 6.1 \\
\hline C85 & 126.2 & H85 & 6.2 \\
\hline C86 & 122.0 & H86 & 9.0 \\
\hline C87 & 128.0 & H87 & 2.2 \\
\hline C88 & 136.0 & H88 & 4.6 \\
\hline C89 & 146.9 & H89 & 5.0 \\
\hline C90 & 129.2 & H90 & 2.0 \\
\hline C91 & 150.4 & H91 & 7.3 \\
\hline C92 & 128.6 & H92 & 5.3 \\
\hline C93 & 166.4 & H93 & 6.2 \\
\hline C94 & 135.0 & H94 & 4.6 \\
\hline C95 & 125.7 & H95 & 2.3 \\
\hline C96 & 118.8 & H96 & 6.0 \\
\hline C97 & 128.5 & H97 & 5.4 \\
\hline C98 & 137.0 & H98 & 6.3 \\
\hline C99 & 179.9 & H99 & 5.9 \\
\hline C100 & 139.7 & H100 & 7.4 \\
\hline C101 & 123.6 & H101 & 0.7 \\
\hline C102 & 126.3 & H102 & 5.6 \\
\hline C103 & 175.5 & H103 & 3.8 \\
\hline C104 & 140.7 & H104 & 5.1 \\
\hline C105 & 128.3 & H105 & 5.9 \\
\hline C106 & 128.7 & H106 & 4.5 \\
\hline C107 & 163.8 & H107 & 6.8 \\
\hline C108 & 130.3 & H108 & 7.7 \\
\hline C109 & 128.1 & H109 & 7.6 \\
\hline C110 & 124.1 & H110 & 5.8 \\
\hline C111 & 125.4 & H111 & -2.0 \\
\hline C112 & 137.8 & H112 & 2.8 \\
\hline C113 & 139.9 & H113 & 7.8 \\
\hline C114 & 125.1 & H114 & 8.7 \\
\hline C115 & 138.2 & H115 & 5.3 \\
\hline C116 & 125.0 & H116 & 7.7 \\
\hline C117 & 172.6 & H117 & 6.0 \\
\hline C118 & 135.7 & H118 & 5.3 \\
\hline C119 & 134.1 & & \\
\hline C120 & 123.5 & & \\
\hline C121 & 128.0 & & \\
\hline C122 & 138.3 & & \\
\hline C123 & 165.9 & & \\
\hline C124 & 138.2 & & \\
\hline C125 & 129.4 & & \\
\hline C126 & 123.4 & & \\
\hline C127 & 178.2 & & \\
\hline
\end{tabular}




\begin{tabular}{ll|} 
C128 & 142.6 \\
C129 & 128.5 \\
C130 & 127.4 \\
C131 & 171.2 \\
C132 & 140.1 \\
C133 & 127.5 \\
C134 & 124.9 \\
C135 & 129.6 \\
C136 & 137.6 \\
C137 & 140.0 \\
C138 & 125.1 \\
C139 & 140.6 \\
C140 & 127.3
\end{tabular}

